\title{
Lateral variations of shallow shear-velocity structure in southwestern Taiwan inferred from short-period Rayleigh waves
}

\author{
Ruey-Der Hwang ${ }^{1 *}$, Guey-Kuen $\mathrm{Yu}^{2}$, Wen-Yen Chang ${ }^{3,4}$, and Jo-Pan Chang ${ }^{1}$ \\ ${ }^{1}$ Center for General Education, Hsing-Kuo University, No. 89, Yuying St., Tainan, 709 Taiwan, ROC \\ ${ }^{2}$ Department of Civil Engineering, Van Nung Institute of Technology, No. 1, Van-Nung Road, Chung-Li, Tao-Yuan, 320 Taiwan, ROC \\ ${ }^{3}$ Department of Natural Sciences and Mathematics, National Science Council, Taipei, 106 Taiwan, ROC \\ ${ }^{4}$ Institute of Geophysics, National Central University, Chung-Li, 320 Taiwan, ROC
}

(Received October 16, 2002; Revised June 5, 2003; Accepted July 2, 2003)

\begin{abstract}
Short-period fundamental-mode Rayleigh waves with periods of $1.1 \sim 5.5 \mathrm{sec}$ were used to investigate the lateral variations of shallow-depth shear-wave velocity structure up to a depth of $8 \mathrm{~km}$ under southwestern Taiwan. Through a priori regionalization, the region was divided into three subregions from the west to the east, and then the regionalized group velocity for each subregion was determined by a standard least-squares technique. By the structure inversion, the study region had obviously lateral velocity variations, which systemically increased from the west region to the east one. On the whole, the shear-wave velocity in the Western Foothills was higher than that in the Western Coastal Plain. Additionally, the three subregions all had a shear-wave velocity of less than $3 \mathrm{~km} / \mathrm{sec}$ with the lowest one in the Western Coastal Plain near the coast, related to the thick sediments. These results were rather consistent with the geological features. For depths larger than $4 \mathrm{~km}$, the velocity-gradient varying with depth in the Western Foothills was lower than that in the Western Coastal Plain. This is likely to interpret the reason that the seismic waves cannot be easily trapped within the Western Foothills; thus the short-period surface waves are poorly developed in that region.
\end{abstract}

Key words: Short-period Rayleigh waves, group velocity, lateral velocity variation.

\section{Introduction}

Short-period surface waves are an important indicator in inferring the shallow-depth shear-wave velocity structure for the upper few kilometers of the crust (e.g. Chung and Yeh, 1997; Hwang et al., 2003). Generally, the generation of short-period surface-wave is mainly dependent on whether the seismic-wave propagation can be trapped within the shallow crust. Two factors, the depth of source and the characteristic of structure, play important roles in exciting the shortperiod surface waves. Previous studies on the short-period surface waves in Taiwan are mainly from the observations of the 1993 Tapu earthquake $\left(\mathrm{M}_{\mathrm{L}}=5.7\right)$, which occurred at Tapu, southwestern Taiwan (Huang et al., 1996) and produced many valuable strong-motion recordings, especially for short-period fundamental-mode Rayleigh waves. Chung and Yeh (1997) first used the short-period fundamental-mode Rayleigh waves from the 1993 Tapu earthquake to examine the shallow crustal structure in southwestern Taiwan, and concluded that the lateral velocity variations exist in this region. After the occurrence of the 1993 Tapu earthquake, several earthquakes successively occurred in southwestern Taiwan, and also brought about the short-period surface waves. These valuable recordings would provide a chance to deeply increase the understandings of the shallow-depth

\footnotetext{
*Present address: Center for General Education, Van Nung Institute of Technology, Chung-Li, Tao-Yuan, 320 Taiwan, ROC.

Copy right (c) The Society of Geomagnetism and Earth, Planetary and Space Sciences (SGEPSS); The Seismological Society of Japan; The Volcanological Society of Japan; The Geodetic Society of Japan; The Japanese Society for Planetary Sciences.
}

crustal structure. In addition, such the shallow structures can also give useful information to the other studies, including seismic-wave propagation, ground motion prediction, earthquake locations, etc. For this reason, in this study we made an attempt to in more detail investigate the lateral variations of the shallow crustal structure in southwestern Taiwan by the short-period fundamental-mode Rayleigh waves through a priori regionalization.

\section{Brief Description of Geological Settings}

Figure 1 shows a geological sketch of southwestern Taiwan. The region is mainly divided into two geological units, which are the Western Coastal Plain and the Western Foothills, respectively (cf. Ho, 1988). From field survey, the two geological units revealed quite different structural features. In the Western Coastal Plain, the existence of the thick sedimentary layers is its principal feature. Comparatively, the Western Foothills has more complicated structures due to the action of thrust faulting (e.g. Suppe, 1980; Ho, 1988). Hence, the Western Foothills is a region where is highly took care in seismic hazard. In the past, many earthquakes once occurred in the Western Foothills and resulted in destruction to the buildings, such as the 1993 Tapu earthquake and the 1998 Rueyli earthquake as depicted in Table 1 and Fig. 1.

\section{Data and Analysis}

Accelerograms provided by the Central Weather Bureau (CWB) were used in this study. Each accelerometer has a flat instrumental response and a full scale of $\pm 2 \mathrm{~g}$. Moreover, the recordings from the strong-motion stations are digitized with 


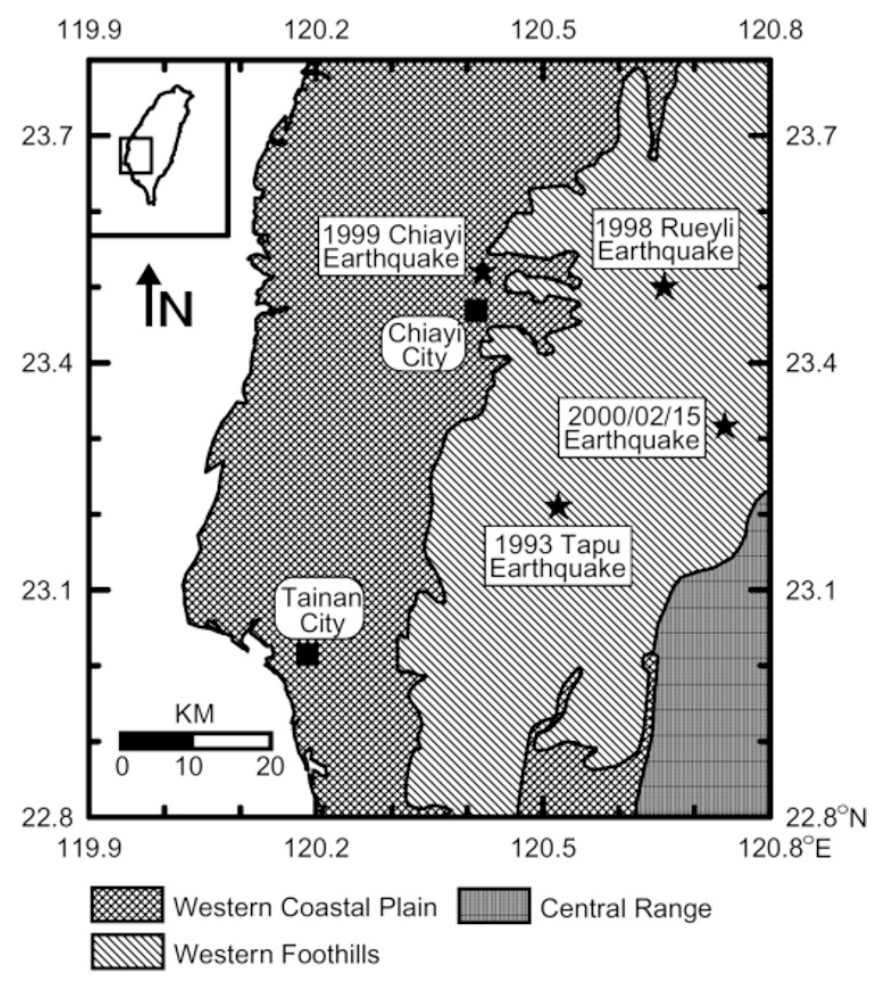

Fig. 1. Geological sketch of southwestern Taiwan. Two main units of geology are the Western Coastal Plain and the Western Foothills. Stars represent the epicenters of these earthquakes used (also see Table 1) and squares denote the two cities, i.e. Chiayi city and Tainan city.

Table 1. Source parameters of five earthquakes used in this study.

\begin{tabular}{cccrrr}
\hline No. & Date & \multicolumn{2}{c}{ Location } & Depth & $\mathrm{M}_{\mathrm{L}}$ \\
\hline 1 & 19931215214943.1 & $23.213^{\circ} \mathrm{N}$ & $120.662^{\circ} \mathrm{E}$ & 12.5 & 5.7 \\
2 & 19980717045114.9 & $23.503^{\circ} \mathrm{N}$ & $120.662^{\circ} \mathrm{E}$ & 2.8 & 6.2 \\
3 & 19991022021856.9 & $23.517^{\circ} \mathrm{N}$ & $120.423^{\circ} \mathrm{E}$ & 16.6 & 6.4 \\
4 & 19991022031017.4 & $23.533^{\circ} \mathrm{N}$ & $120.431^{\circ} \mathrm{E}$ & 16.7 & 6.0 \\
5 & 20000215213318.1 & $23.316^{\circ} \mathrm{N}$ & $120.740^{\circ} \mathrm{E}$ & 14.7 & 5.6 \\
\hline
\end{tabular}

*Source parameters were routinely reported by the CWB. Numbers 1, 2 and 3 are the 1993 Tapu earthquake, the 1998 Rueyli earthquake and the 1999 Chiayi earthquake, respectively. The fourth earthquake is an aftershock of the 1999 Chiayi earthquake.

a 16-bit resolution at 200 samples per second (cf. Liu et al., 1999). For this reason, the surface-wave group delay caused by the instrumental response can be ignored. Figure 2 shows several vertical-component accelerograms generated by the 1993 Tapu earthquake and the 1999 Chiayi earthquake, respectively (also see Table 1 and Fig. 1). In Fig. 2, these accelerograms recorded at a number of stations situated on the Western Coastal Plain presented a notable feature that the longer period signals appear after the $S$-wave and persist for tens of seconds. For clearly showing these signals, we directly integrated the vertical-component accelerograms twice to obtain their corresponding displacements. Subsequently, the displacements were filtered by a Butterworth filter with a frequency-band of $0.1 \sim 5 \mathrm{~Hz}$ (Fig. 2). The shortperiod Rayleigh waves, then, were seen obviously. In these displacements, the longer period signals early arrived at the station as compared with the shorter period ones in that these recordings showed a characteristic of normal dispersion, for which the group velocity increases with period (also see Fig. 3).
In this study, the Multiple Filter Technique (MFT: Dziewonski et al., 1969) was used to measure the group velocity of the short-period Rayleigh-wave. Furthermore, in order to refine these dispersive waves, we also employed the Phase-Matched Filter (Herrin and Goforth, 1977) to modify the original dispersion curves, determined by the MFT, for eliminating contamination of noise and multi-pathing. Some unsuitable seismograms recorded in the nodal direction of the source have been eliminated in the data processing. The group velocities from the multi-pathing were also excluded through a detailed examination based on the narrow band-pass filter (Herrmann, 1973) as MFT. Because these Rayleigh-wave paths traveled over the two different geological units (Figs. 3 and 4), it was adequate to investigate the lateral velocity variations and the shallow crustal structure beneath the southwestern Taiwan region. Lastly, 61 shortperiod Rayleigh-wave paths with periods of $1.1 \sim 5.5$ seconds were used to yield the examination of shallow crustal structure (Fig. 4). 
1993 Tapu Earthquake

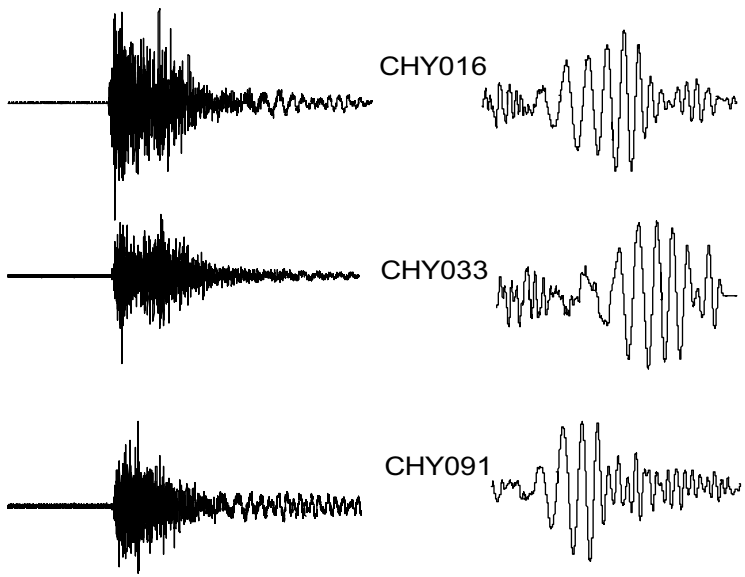

1999 Chiayi Earthquake

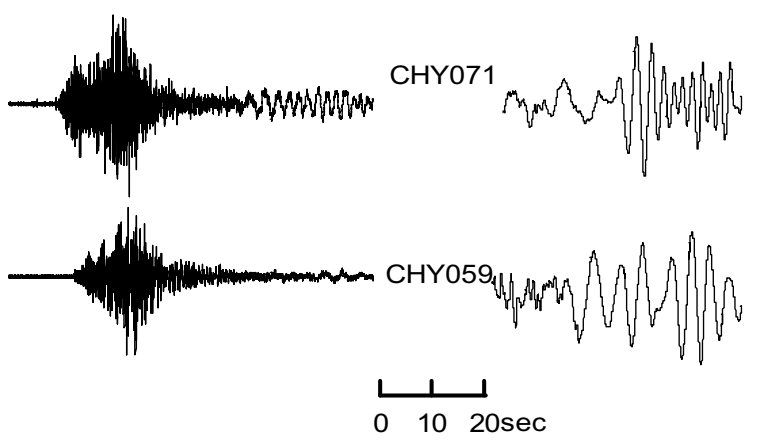

Fig. 2. Several vertical-component accelerograms in $\mathrm{cm} / \mathrm{sec}^{2}$ (left) and their corresponding displacements in $\mathrm{cm}$ (right), generated by the $1993 \mathrm{Tapu}$ earthquake and the 1999 Chiayi earthquake, are presented. Displacement seismograms from the double integrations of the accelerograms are filtered at frequency range of $0.1 \sim 5 \mathrm{~Hz}$.
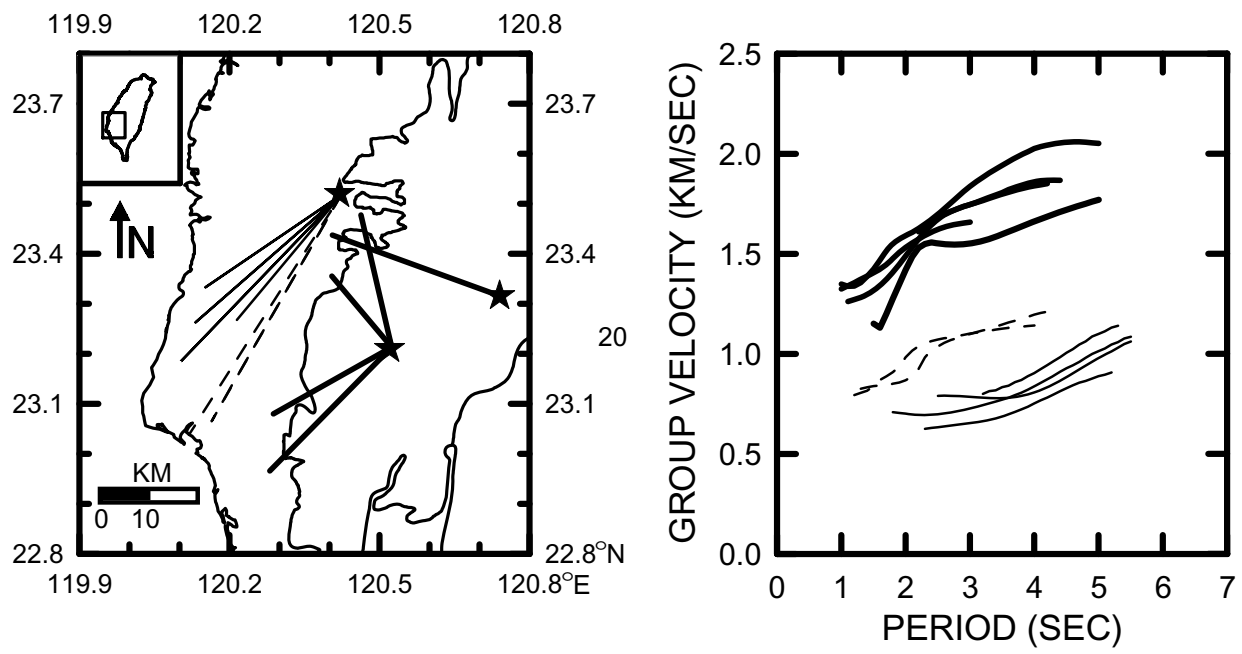

Fig. 3. Left diagram shows a few ray-paths across the study region. Ray-paths traveling across the Western Foothills and Western Coastal Plain are denoted by thick lines, thin solid lines and dashed lines, respectively. Also, the corresponding group velocities for these Rayleigh waves by the MFT analysis are shown in the right diagram.

\section{Results and Discussion}

\subsection{A priori regionalization}

From Fig. 3, the group velocities for Rayleigh-wave paths across the study region exhibited a quite wide variation from $0.6 \sim 1.3 \mathrm{~km} / \mathrm{sec}$ at a period of $1.1 \mathrm{sec}$ to $0.9 \sim 2.1 \mathrm{~km} / \mathrm{sec}$ at a period of $5 \mathrm{sec}$. This implied that the lateral velocity variations are capable of being anticipated in southwestern Taiwan. Although the short-period surface waves were unfavorably generated in the Western Foothills on account of the structural complexity and the radiation pattern of source (cf. Chung and Yeh, 1997), a few Rayleigh-wave paths almost only passing across the Western Foothills could still show 


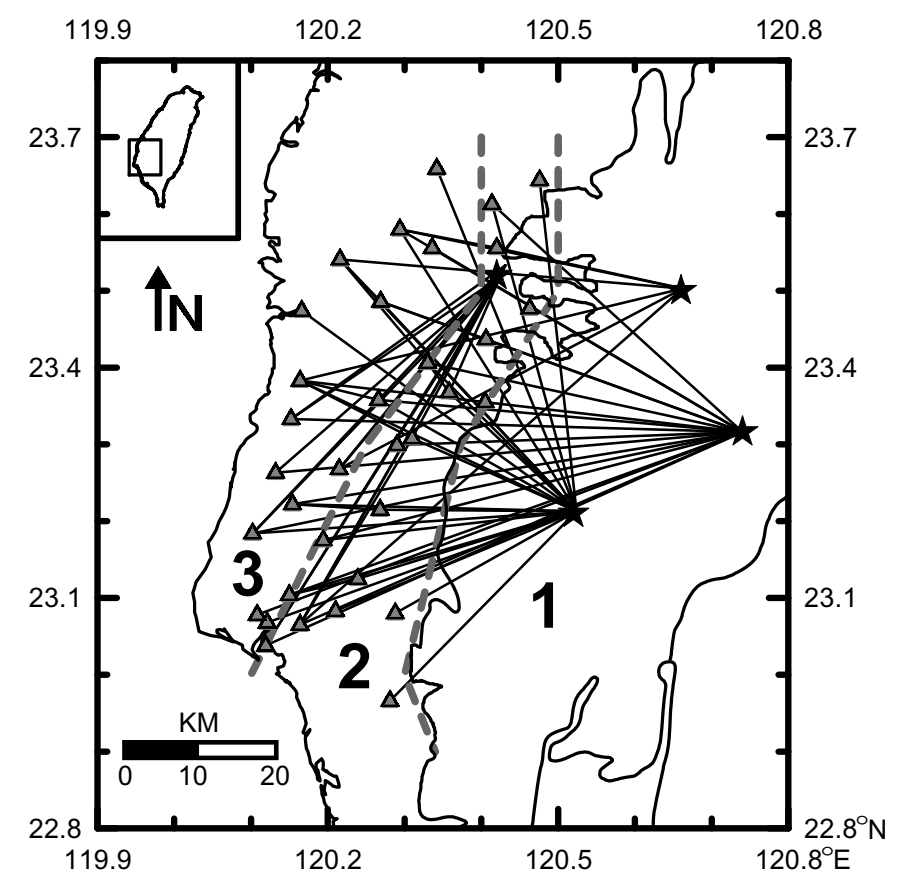

Fig. 4. Sixty-one Rayleigh-wave paths used in this study are shown in solid lines. Stars and triangles denote the earthquakes and the stations. Dashed lines divided the region into three subregions, numbered by 1,2 and 3 , respectively.

the characteristics of dispersive waves (Fig. 3). Also, we inspected a number of ray-paths, which purely passed through the two geological provinces, and found out a significant discrepancy between the group velocities. As shown in Fig. 3, apparently, the group velocities in the Western Foothills were higher than those in the Western Coastal Plain. In addition, a remarkable feature between these observations was that the group velocities in the Western Coastal Plain expressed the obvious differences as well, that is, the group velocities to the west of the Western Coastal Plain were lower than those to the east one (Fig. 3). This indicates that the velocity variation also exist in the Western Coastal Plain. According to such features as mentioned above, we divided the region into three subregions: one is the Western Foothills denoted by Region 1 and the two others are Region 2 and Region 3 in the Western Coastal Plain as displayed in Fig. 4.

In accordance with the pure-path method (cf. Knopoff, 1969), the group-delay time for a given ray-path can be expressed in the following form.

$$
t_{i}(T)=\frac{L_{i}}{V_{0 i}(T)}=\sum_{j=1}^{n} \frac{L_{i j}}{V_{j}(T)}
$$

where $t_{i}(T)$ and $L_{i}$ are the travel time in second at a particular period $(T)$ and the epicentral distance in $\mathrm{km}$ for the $i$ th path, respectively. $L_{i j}$ is the partial length of the $i$ th path traveling across the $j$ th subregion in $\mathrm{km} . V_{o i}(T)$ is the observed group velocity of the $i$ th path, and $V_{j}(T)$ is the group velocity of the $j$ th subregion to be determined. Equation (1) can be solved by a standard linear inversion technique based on a least-squares method (cf. Menke, 1984).

Figure 5(a) shows the regionalized group velocities for the three subregions. Results show that the regionalized group velocities gradually increased from the west region to the east one to account for the existence of lateral heterogene- ity. Comparing the group velocities of Fig. 3 with those of Fig. 5(a), we can clearly see that there are high consistencies between the two results. This further indicates that the regionalization employed in this study is reasonable. The regionalized group velocities in Regions 2 and 3 were smoother than those in Region 1 (Fig. 5(a)). Hence, the structure under the Western Coastal Plain is probably simpler than under the Western Foothills. In Fig. 5(a), the groupvelocity differences between the Region 2 and Region 3 almost kept a value of $0.4 \mathrm{~km} / \mathrm{sec}$ over the whole period range. This seems to imply that the structures in the two regions have similar velocity-gradient variations with depth. For periods less than $2 \mathrm{sec}$, the regionalized group velocities in Region 1 largely increased relative to the two other regions. This might suggest that there is a large velocity variation at the shallower depths in Region 1.

\subsection{Shallow-depth crustal structure}

It's well-known that there is a nonlinear relationship between the dispersion curves of surface-wave and the velocity structures under the Earth. This would make the inversion problem uneasily solved by a least-squares technique. Hence, a quasi-linear relationship will be retrieved through Taylor series expansion when the high-order terms are neglected. Because the relatively large perturbations to the surface waves are from the $S$-wave velocity (shear-wave velocity) than from the $P$-wave velocity and density, only the shear-wave velocity is determined in the inversion process. Then, the formula can be written as follows.

$$
\Delta U\left(T_{j}\right)=\sum_{i=1}^{N}\left(\frac{\partial U\left(T_{j}\right)}{\partial \beta_{i}}\right) \Delta \beta_{i}
$$

where $\Delta U\left(T_{j}\right)$ is the difference between the observed and the predicted group-velocity at the $j$ th period $\left(T_{j}\right)$, and $\Delta \beta_{i}$ is the resulting difference in the $S$-wave velocity of the $i$ th 
SHEAR WAVE VELOCITY (KM/SEC)
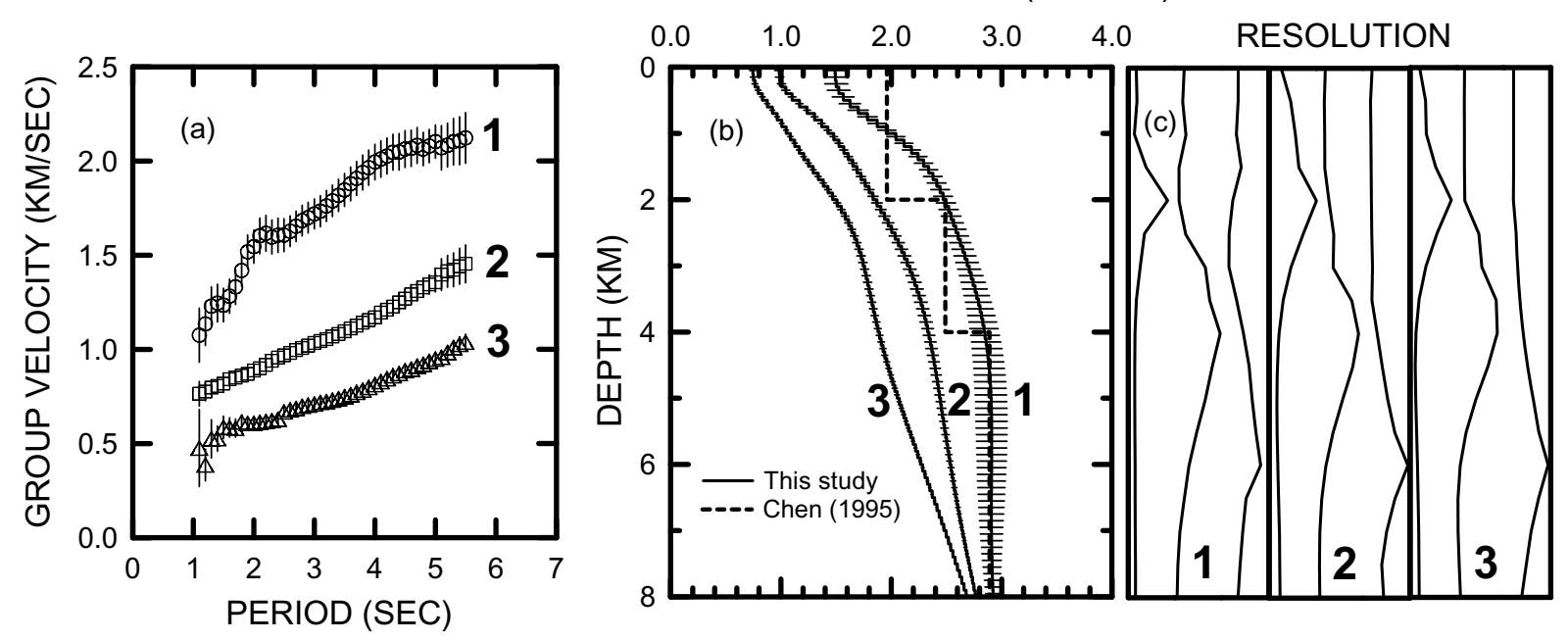

Fig. 5. (a) Regionalized group velocities for the three subregions are determined through a standard least-squares method. Vertical lines denote the standard deviation after the inversion. (b) Shallow-depth shear-velocity structures are determined by the inversion of the regionalized group velocities for the three subregions. Error bars are also shown in horizontal lines. (c) Resolving kernels at several given depths for the three subregions.

layer between adjacent inversions. $N$ is the number of layers, and $\frac{\partial U\left(T_{j}\right)}{\partial \beta_{i}}$ is the partial derivative of the group-velocity of the $j$ th period with respect to the $S$-wave velocity of the $i$ th layer.

To solve Eq. (2), we used an iterative linear inversion technique developed by Herrmann (1991). Owing to the lack of the detailed layered velocity model in the study region for the shallow-depth crust, we used a half-space structure with $S$-wave velocity of $3 \mathrm{~km} / \mathrm{sec}$ as the initial model and adopted an inversion process with a smoothness constraint between velocity models, proposed by Constable et al. (1987), to infer the shear-wave velocity structure under southwestern Taiwan. In the structure inversion, the very shallow soft alluvial material and the topography would influence the inversion results at the very shallow depths of up to tens of meters. Hence, when using the surface waves with higher frequency contents to invert the velocity structure, one should positively introduce the very shallow alluvial materials and the topography into the inversion process. Since the short-period Rayleigh waves with periods greater than $1 \mathrm{sec}$ were used in this study, we considered that such data are not able to resolve the very shallow structure up to tens of meters. On the other hand, our purpose of this study was to principally describe the velocity variations for the upper few kilometers of the crust. Hence, the very shallow structure and the topography variation have small effects on our results. Figure 5(b) shows the results of the structure inversion for the three subregions. Obviously, the shear-wave velocity structures exhibited the lateral variations decreasing from the east to the west (Fig. 5(b)). The results are similar to a study of Hwang et al. (2003) and geological survey (cf. Ho, 1988), and are probably controlled by orogeny and deposition in Taiwan. Resolving kernels of the three subregions for several given depths (2, 4 and $6 \mathrm{~km})$ were shown in Fig. 5(c). Because of the smoothing inversion used in this study, the resolving kernel is not a perfect value $(\sim 1.0)$ and spreads outward over the whole depths. However, these resolving kernels are still recognizable to indicate the better depth resolution for sev- eral given depths in Fig. 5(c). From Fig. 5(b), the shear-wave velocity in Region 1 was larger than that in the other two regions, and that in Region 3 was the lowest one. For depths less than $2 \mathrm{~km}$, Region 1 had a higher velocity-gradient variation as compared with Regions 2 and 3. This could be related to the complicated structure in the Western Foothills where there are some actions of the thrust faulting to result in the imbricated structures (e.g. Suppe, 1980). At depths greater than $4 \mathrm{~km}$, the shear-wave velocity in Region 1 almost kept a constant, about $2.9 \mathrm{~km} / \mathrm{sec}$, to demonstrate that the seismic waves are easier to be trapped within the layers of Regions 2 and 3 than within that of Region 1. In other words, the well-developed short-period surface waves are easily observed at some stations located on the Western Coast Plain as mentioned by Chung and Yeh (1997). In Fig. 5, the velocities at depths less than $8 \mathrm{~km}$ for the three subregions have a shear-velocity of less than $3.0 \mathrm{~km} / \mathrm{sec}$, associated with the thick sediments and in agreement with a study of the 1-D $S$ wave structure of western Taiwan from Chen (1995). Moreover, in Region 1, the velocities at depths of 4 to $8 \mathrm{~km}$ are accordant with Chen's results; relatively, at depths of 2 to $4 \mathrm{~km}$, Chen's results approximate to the average values of Regions 1 and 2 in shear-wave velocity. For depths less than $2 \mathrm{~km}$, our results expressed significant velocity variations as compared with the 1-D model (Chen, 1995). Thus, through the analysis of the short-period Rayleigh waves, the detailed shallow-depth shear-wave structures can be determined than done previously. Owing to the large changes in structures between the Western Coast Plain and the Western Foothills, the mode conversion of seismic waves would occur at the border between the two geological units when the seismic waves had a suitable incident angle (i.e. critical angle) from a material to the other one. Hence, the short-period Rayleigh waves could be probably caused by the mode conversion from the $S$-wave (Chung and Yeh, 1997). However, the short-period Rayleigh waves from the mode conversion should propagate along the boundary of the two different geological provinces. For this reason, the short-period Rayleigh waves, observed 
at the stations that are distance from the source, are mainly controlled by the shallow structures rather than by the mode conversion. Although a study of Chung and Yeh (1997) has pointed out the lateral velocity variations in the area on the basis of the epicentral distances, such a simpler regionalization is not sufficient to account for systemic differences in the shear-wave velocity structure under southwestern Taiwan. Based on Chung and Yeh's regionalization, we do not seem to consider the matter that there are good consistencies between the modeling and the observed seismograms from their studies.

From this study, not only can we construct the shallow crustal structures, but clearly show the lateral velocity variations from relatively large seismic data set in the southwestern Taiwan region through a priori regionalization. In the future, the forward modeling of the seismograms calculated in light of the laterally inhomogeneous structure received from our study will be the next subject.

\section{Conclusions}

The obvious lateral heterogeneity of the shallow-depth crustal structure in southwestern Taiwan is inferred through the inversion of the short-period Rayleigh waves with periods of $1.1 \sim 5.5 \mathrm{sec}$. In this region, systemically increasing from the west region to the east one seems to imply that the structure is approximately parallel to the main structure of Taiwan. The three subregions have a shear-velocity of less than $3.0 \mathrm{~km} / \mathrm{sec}$ with the lowest one in Region 3 near the coast. Thick sediments in the study region are applicable to account for such structures. The velocity in the Western Foothills, in general, is larger than that in the Western Coastal Plain. Such structure variations are probably related to orogeny and deposition in Taiwan. From our results, the structure in Region 1, i.e. the Western Foothills, is possibly disadvantageous to generate the well-developed short-period surface waves.

Acknowledgments. We would like to express our thanks to the Central Weather Bureau for providing us with seismic data. This study was financially supported by the National Science Council, R.O.C. under Grant Nos. NSC89-2921-M-001-009-EAF and NSC90-2116-M-008-003.

\section{References}

Chen, Y.-L., Three dimensional velocity structure and kinematic analysis in Taiwan area, 172 pp., M.S. Thesis, National Central University, ChungLi, Taiwan, 1995.

Chung, J.-K. and Y.-T. Yeh, Shallow crustal structure from short-period Rayleigh-Wave dispersion data in southwestern Taiwan, Bull. Seism. Soc. Am., 87, 370-382, 1997.

Constable, S. C., R. L. Parker, and C. G. Constable, Occam's inversion: A practical algorithm for generating smooth models from electromagnetic sounding data, Geophysics, 52, 289-300, 1987.

Dziewonski, A., S. Bloch, and M. Landisman, A technique for the analysis of transient seismic signals, Bull. Seism. Soc. Am., 59, 427-444, 1969.

Herrin, E. and T. Goforth, Phase matched filters: Application to the study of Rayleigh waves, Bull. Seism. Soc. Am., 67, 1250-1275, 1977.

Herrmann, R. B., Some aspects of band-pass filtering of surface waves, Bull. Seism. Soc. Am., 63, 703-711, 1973.

Herrmann, R. B., Computer Programs in Seismology, Vol. IV: Surface Wave Inversion, Department of Earth and Atmospheric Sciences, Saint Louis University, USA, 1991.

Ho, C.-S., An introduction to the geology of Taiwan: Explanatory text for the geologic map of Taiwan, 164 pp., Minist. Econ. Aff., Taipei, ROC, 2nd ed., 1988.

Huang, B. S., K. C. Chen, and Y. T. Yeh, Source parameters of the December 15, 1993 Tapu earthquake from first P-motions and waveforms, J. Geol. Soc. China, 39, 235-250, 1996.

Hwang, R.-D., G.-K. Yu, and W.-Y. Chang, 3-D shallow shear-velocity structure around the source area of the 1999 Chi-Chi (Taiwan) earthquake by tomographic inversion of short-period Rayleigh waves, J. Geophys. Res., 2003 (submitted).

Knopoff, L., Phase and group slownesses in inhomogeneous media, J. Geophys. Res., 74, 1701, 1969.

Liu, K.-S., T.-C. Shin, and Y.-B. Tsai, A free-field strong motion network in Taiwan: TSMIP, TAO, 10, 373-396, 1999.

Menke, W., Geophysical Data Analysis: Discrete inversion theory, 260 pp., Academic Press, San Diego, 1984.

Suppe, J., Imbricated structure of western foothills belt, south-central Taiwan, Petro. Geol. Taiwan, 17, 1-16, 1980.

R.-D. Hwang (e-mail: red@ftp1.gep.ncu.edu.tw or red@mail.hku.edu. tw), G.-K. Yu, W.-Y. Chang, and J.-P. Chang 